\title{
Liquid Soap Dosage Form
}

National Cancer Institute

\section{Source}

National Cancer Institute. Liquid Soap Dosage Form. NCI Thesaurus. Code C68953.

A solution or suspension composed of an anionic surfactant used for cleansing. 